\title{
The effect of smoking on inflammatory cell infiltrate subtypes in gingival tissue of patients with chronic periodontitis
}

Mehrdad Radvar ${ }^{1}$, Hooman Shafaee ${ }^{2}$, Nooshin Mohtasham², Farid Shiezadeh³, Mona Zamanpour ${ }^{4}$

${ }^{1}$ Associate Professor, Dental Research Center, Mashhad University of Medical Sciences, Mashhad, Iran

${ }^{2}$ Assistant Professor, Dental Research Center, Mashhad University of Medical Sciences, Mashhad, Iran

${ }^{3}$ Associate Professor, Oral \& Maxillofacial Diseases Research Center, Mashhad University of Medical Sciences, Mashhad, Iran

${ }^{4}$ Assistant Professor, Department of Periodontics, School of Dentistry, Khorasan Shomali University of Medical Sciences, Boujnord, Iran

${ }^{5}$ DDS, Post-graduate Student of Operative Dentistry, Department of Operative Dentistry, School of Dentistry, Mashhad University of Medical Sciences, Mashhad, Iran

\section{Type of article: Original}

\begin{abstract}
Background: Examinations on blood samples and gingival crevicular fluid of subjects with chronic periodontitis showed that smoking increased production of cytokines.

Objective: To evaluate the expression of immune markers on mononuclear inflammatory cell infiltrate at periodontitis and healthy tissue among smoking and non-smoking subjects.

Methods: This case-control study was performed on 41 patients who referred to a clinic of periodontology at a Mashhad dental school in Iran in 2016. The participants were all of Iranian Khorasanian ethnicity with age range of 35-65 years. Gingival biopsies were obtained during routine periodontal flap procedure. Immunohistochemistry using markers of CD20, CD3, CD68, and CD45RO was carried out. Data was analyzed by SPSS version 15, using one-way ANOVA and Tukey HSD test.

Results: Nonsmoker subjects showed significantly greater numbers of CD20+, CD68+, CD3+ cells compared to smoker subjects, both at healthy and periodontitis tissue biopsies $(\mathrm{p}<0.00)$, whereas there was no significant difference in terms of $\mathrm{CD} 45 \mathrm{RO}(\mathrm{p}=0.120)$.

Conclusion: Cigarette smoking, results in infiltrative mononuclear chronic inflammatory cells reduction in connective periodontium.
\end{abstract}

Keywords: Chronic periodontitis, cigarette smoking, immune markers

\section{Introduction}

Chronic periodontitis (CP) is a common inflammatory disease which involves the supporting tissue of teeth, and gradually destroys alveolar bone and connective tissue $(1,2)$. It is widely accepted that the destruction of periodontal tissue is a result of host immune inflammatory response caused by periodontal microorganisms $(3,4)$. The white blood cells (WBCs) and macrophages are triggered to produce inflammatory mediators, including cytokines, chemokines and proteolytic enzymes, which may cause tissue degradation and bone resorption (5,6). A major risk factor for the development and progression of CP is cigarette smoking (7-11). The destructive effect of smoking has been attributed to an alteration in the microbial flora and host immune inflammatory response $(12,13)$. Nicotine in cigarettes provokes inflammation and causes vasoconstriction and scar formation (14). Other cytotoxic substances included in cigarettes have an important role in cell migration and secretion of inflammatory mediators $(15,16)$. The direct effect of smoking on periodontal tissue includes gingival fibrosis, decreased bleeding on probing (BOP) and decreased gingival crevicular fluid (GCF) (17). In general, it has been shown that the clinical signs of inflammation

\section{Corresponding author:}

Dr. Mona Zamanpour, Department of Operative Dentistry, School of Dentistry, Mashhad University of Medical Sciences, Mashhad, Iran. Tel: +98.9153176671, E-mail: zamanmoona@gmail.com

Received: April 14, 2017, Accepted: June 14, 2017, Published: August 2017

iThenticate screening: June 04, 2017, English editing: June 27, 2017, Quality control: July 12, 2017

(C) 2017 The Authors. This is an open access article under the terms of the Creative Commons Attribution-NonCommercialNoDerivs License, which permits use and distribution in any medium, provided the original work is properly cited, the use is non-commercial and no modifications or adaptations are made. 
and BOP are less evident in smokers compared with non-smokers $(18,19)$. Souto et al. $(20)$ reported that smoking decreased both inflammatory infiltrate and dendritic cells in samples of chronic gingivitis. Smoking also has a deleterious effect on the outcome of periodontal treatments $(12,21,22)$. Examinations on blood samples and gingival crevicular fluid of subjects with chronic periodontitis showed that smoking increased production of cytokines $(23,24)$. Fatemi et al. (25) reported that toll like receptors (TLR) 2 and 4 expression were higher among smoker subjects. Low levels of clinical inflammation among smokers on one hand and increase in bone resorption and tissue degradation on the other, may seem paradoxical and the proportion of chronic inflammatory cell infiltrates needs to be better understood. Therefore, the aim of this study was to examine the chronic inflammatory cell infiltrates in gingival tissue of affected periodontitis and healthy periodontal gingiva of smoker and non-smoker subjects using immunohistochemistry (IHC).

\section{Material and Methods}

\subsection{Research design and participants}

The study population was selected from a pool of referrals to the Department of Periodontology of Mashhad Dental School in 2016. Since similar studies have not been done, we performed this study as a pilot. The power of study indicated that the sample size was sufficient (study power: 90\%). The study groups consisted of 20 smoker, and 21 non-smoker patients. These patients required periodontal surgery because of their periodontal disease. Only heavy smokers (case) and never smokers (control) were included in the sample in order to minimize the masking effect of inclusion of occasional smoker patients. Heavy smoking was defined as smoking twenty or more cigarettes per day as reported by the patients themselves. The patients who had systemic disease or used antibiotics within the past month were excluded from the study. No biochemical analysis was conducted to verify and quantify the smoking status of patients. All patients had periodontitis affected sites. Therefore, an initial phase of periodontal treatment including oral hygiene instruction and non-surgical mechanical debridement was carried out for all patients. Six weeks following the initial phase, sites still showing pocket depth $(\mathrm{PD}>5 \mathrm{~mm})$ and $\mathrm{BOP}+$ were allocated to surgical pocket elimination. Each patient provided two biopsy samples which were harvested during his surgery. One sample was from periodontally diseased sites $\mathrm{PPD}>5$ and $\mathrm{BOP}+$. The other biopsy was taken from adjacent healthy sites. Therefore, the study consisted of 4 groups. In groups one and three the patients were smokers who smoked one or more pack of cigarettes. Mild smokers were deliberately excluded in order to prevent masking of any possible differences with non-smokers. Group two and four consisted of non-smoker subjects. In groups 1 and 2, biopsy samples were taken from periodontally healthy sites whereas in groups 3 and 4 , the sampled sites periodontal pockets depth $>5 \mathrm{~mm}$ and BOP. The age range of patients were between 35 and 65 years. Patients on medication known to interfere with periodontal pathology such as antibiotics or anti-inflammatory drugs were excluded. Furthermore, aggressive periodontitis patients were not included in the study. All patients signed a written consent form prior to inclusion into the study. The biopsies were taken 3 to $5 \mathrm{~mm}$ from the papilla tip ensuring that it included oral epithelium and sulcular epithelium, junctional epithelium and connective tissue. A horizontal mucoperiosteal incision at right angle to the buccal interproximal bone was done, separating the papilla tip from the rest of gingival. An interdental knife (Goldmanfox, HU-Friedy Mfg Co, Chicago, IL) was used to separate the excised gingival.

\subsection{Immunohistochemistry}

For IHC, four slices with a thickness of $4 \mu \mathrm{m}$ were prepared from each paraffin-embedded section. The sections were fixed on poly-L-Lysine-coated glass slides. Deparaffinized and rehydrated slides were incubated for 30 minutes in 3\% hydrogen peroxide/methanol to stop endogenous peroxidase activity, and then irrigated with phosphate-buffered saline (PBS) for 20 minutes. For antigen retrieval, the sections were microwaved in citrate solution (0.01 M, pH 6.0) for 35 minutes. Specimens were incubated with the primary anti-HSP27 monoclonal antibody (Catalogue No. Clone 2B4; Novocastra Laboratories Ltd, Newcastle, U.K.) and primary anti-HSP27 monoclonal antibody (Catalogue No. Clone 58 F12; Novocastra Laboratories Ltd, Newcastle, U.K.). Specimens were incubated with the primary antibodies for one hour at room temperature. The sections were rinsed three times with PBS at room temperature. The secondary antibody was applied, and immune complexes were identified by Streptavidin peroxidase (Novo Link Polymer detection system). After washing three times with PBS, the immune reactivity was visualized by $3,3^{\prime}$-diaminobenzidine and hydrogen peroxide. Finally, slides were counterstained with hematoxylin and cover slipped with a synthetic mounting media, and then slides were examined by light microscopy. The immunohistochemical staining kit was the Novo Link Polymer detection system (RE7140-K 250T), which is an updated version of Biotin Labeled Streptavidin (LSAB). CD3 ready to use monoclonal antibody (Novocastra Laboratories Ltd., RTU-CD3-PS1), CD20 ready to use monoclonal antibody (Novocastra Laboratories Ltd., RTU-CD20-L26), CD45RO ready to use monoclonal antibody (Novocastra Laboratories Ltd., RTU-UCHL1) 
and CD68 Lyophilized Concentrated Monoclonal Antibody (Novocastra Laboratories Ltd., NCL-CD68-KP1) were used according to the manufacturer's instruction (Novocastra). No other elements of systemic immune response were measured on patients. For microscopic evaluation within each slide, ten microscopic fields with high density of cells and without tissue defect were selected by the examiner, and evaluated using a light microscope (Leica DMRB). Positive cells were counted under $\times 100$ magnification and this was performed by two independent examiners unaware of study groupings. Micrographs were captured using a Leica Galen III microscope and digital camera (SSSC-DC.58 AP, Sony) (Figures 1, 2).

\subsection{Statistical analysis}

Differences between groups in terms of each histochemical marker were carried out using One-way ANOVA test. Furthermore, Tukey HSD test was performed as post hoc test. We used SPSS version 15 (SPSS Inc. Chicago, Illinois, USA) for data analysis (Confidence interval: 95\%).
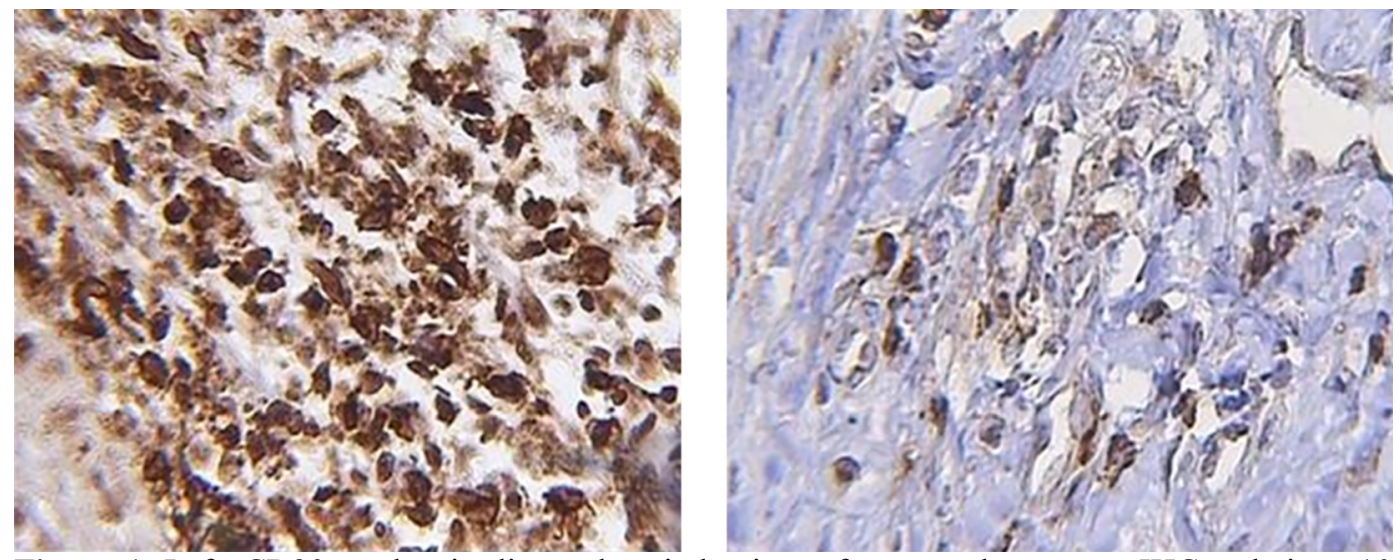

Figure 1. Left: CD20 marker in diseased periodontium of non-smoker group. IHC technique 100X. Right: CD20 marker in diseased periodontium of smoker group. IHC technique 100X.
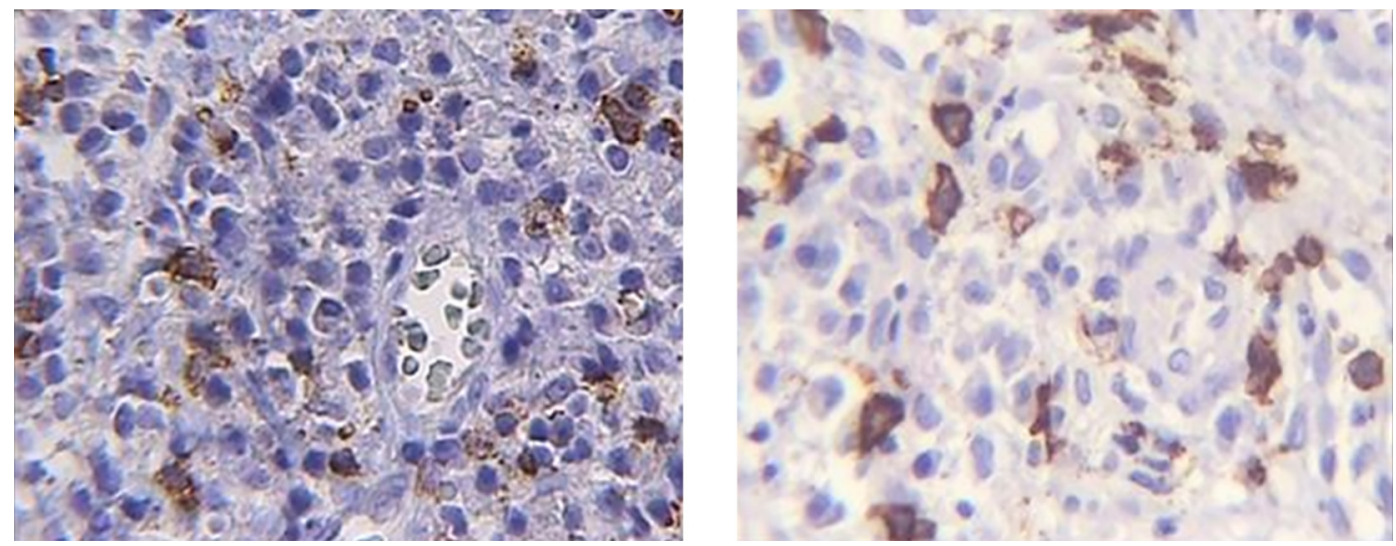

Figure 2. Left: CD3 marker in diseased periodontium of non-smoker group. IHC technique 100X. Right: CD3 marker in diseased periodontium of smoker group. IHC technique 100X.

\section{Results}

In total, 82 specimens were available for the analysis, of which 42 blocks belonged to non-smoker groups and 40 to smoker groups. (Half of the blocks were related to the healthy group and the other half were related to the periodontitis group) Only one section for CD68 marker in smoker groups was eliminated because of the low quality of tissue specimen. The number of different infiltration cells with different markers in smoker and non-smoker healthy gingiva (no periodontitis) and periodontitis gingiva was shown in Table1. Smoker patients had more CD3, CD68, and CD20 than non-smokers and the differences were significant. However, for CD45RO, there was no significant difference between the two groups. Post-hoc Tukey HSD test was also performed and the results were indicated in Table 1. The results showed that the proportion of CD45to CD3 in the smoker group was more than the non-smoker group, either in healthy or diseased sites $(\mathrm{p}=0.019)$. However, the proportion of macrophage CD68 to 
CD3 was lower in the smoker group than the non-smoker group, but this difference was not significant. The proportion of CD20 to CD3 in healthy and diseased sites was similar for both groups.

Table 1. Immunohistochemical evaluation for amount of infiltration cells in the smoker and non-smoker groups in healthy and periodontitis sites.

\begin{tabular}{|c|c|c|c|c|c|}
\hline Markers & Groups & Subgroups & $\mathrm{n}$ & Mean \pm SD & p-value \\
\hline \multirow[t]{4}{*}{ CD45RO } & \multirow[t]{2}{*}{ Smoker } & Healthy & 20 & $33.40 \pm 28.79$ & \multirow[t]{4}{*}{0.120} \\
\hline & & Periodontitis & 21 & $47.19 \pm 34.20$ & \\
\hline & \multirow[t]{2}{*}{ Nonsmoker } & Healthy & 21 & $31.67 \pm 21.98$ & \\
\hline & & Periodontitis & & $54.83 \pm 55.29$ & \\
\hline \multirow[t]{4}{*}{ CD20 } & \multirow[t]{2}{*}{ Smoker } & Healthy & 20 & $19.70 \pm 19.96^{\mathrm{a}}$ & \multirow[t]{4}{*}{0.0002} \\
\hline & & Periodontitis & 21 & $21.28 \pm 13.84^{\mathrm{ac}}$ & \\
\hline & \multirow[t]{2}{*}{ Nonsmoker } & Healthy & 21 & $35.05 \pm 27.78^{\mathrm{ab}}$ & \\
\hline & & Periodontitis & 22 & $50.78 \pm 32.75^{\mathrm{b}}$ & \\
\hline \multirow[t]{4}{*}{ CD68 } & \multirow[t]{2}{*}{ Smoker } & Healthy & 19 & $1.79 \pm 1.39^{\mathrm{b}}$ & \multirow[t]{4}{*}{$<0.0001$} \\
\hline & & Periodontitis & 21 & $2.52 \pm 2.71^{b}$ & \\
\hline & \multirow[t]{2}{*}{ Nonsmoker } & Healthy & 21 & $10.62 \pm 11.20^{\mathrm{a}}$ & \\
\hline & & Periodontitis & 22 & $11.50 \pm 8.43^{\mathrm{a}}$ & \\
\hline \multirow[t]{4}{*}{ CD3 } & \multirow[t]{2}{*}{ Smoker } & Healthy & 19 & $46.53 \pm 46.15^{b}$ & \multirow[t]{4}{*}{$<0.0001$} \\
\hline & & Periodontitis & 21 & $54.76 \pm 42.58^{\mathrm{bc}}$ & \\
\hline & \multirow[t]{2}{*}{ Nonsmoker } & Healthy & 21 & $94.05 \pm 50.53^{\mathrm{ac}}$ & \\
\hline & & Periodontitis & 24 & $124.04 \pm 80.04^{\mathrm{a}}$ & \\
\hline
\end{tabular}

Figures with same alphabetical letter superscription have no significant differences (Tukey HSD test)

\section{Discussion}

In our study, gingival biopsies were examined by immuno-histochemical technique which quantified the amount of $\mathrm{CD} 3+, \mathrm{CD} 20+, \mathrm{CD} 68+$ and $\mathrm{CD} 45 \mathrm{RO}+$ cells in inflammatory infiltrated gingival tissue. Common findings in cigarette smokers is that visual signs of inflammation are diminished among smokers (26). BOP and gingival crevicular fluid (GCF) volumes are reduced (27) and yet, periodontal bone loss is aggravated. In fact, smoking is the strongest environmental risk factor for periodontal attachment loss. The reduction in inflammation together with increased attachment loss sounds somewhat paradoxical. Morozumi et al. showed that smoking cessation increased gingival blood flow and gingival crevicular fluid (28). Ryder et al showed that chronic cigarette smoking reduced gingival blood circulation (29). Johnson et al. showed that smokers have less BOP+ sites, and they found more $\mathrm{CD} 3+, \mathrm{CD} 8+, \mathrm{CD} 4+$ cells in periodontal tissue in smokers compared with non-smokers. However, the number of Bcells showed no difference between the groups. They concluded that the greater number of T-cells in smokers was one reason for more periodontal destruction. The result of this study was different to our study meanwhile, the mentioned study didn't examine healthy sites in smokers and non-smokers and the sampling and laboratory methods were different. (30) These studies indicated the vasoconstrictor effect of cigarette smoking which may be one reason for the reduction in the number of inflammatory cells. Giannopolou et al. showed that reduction in IL-4 level in smokers prevented the proliferation and function of B-cells (31). Orbach et al. used flow-cytometric analysis and showed that CD4+ and CD8+ cells in smokers were lower than those in non-smokers. Although this study examined limited factors it was in accordance to our study. It should be noted that flowcytometric analysis is more sensitive than immunohistochemical techniques (32). In most of the previous studies, separate test and control groups had been used for comparison of healthy and inflamed tissue (15). However, in our study, biopsies were obtained from two different sites (healthy tissue and diseased tissue) within the same patient suffering from chronic periodontitis. Therefore, it was possible to evaluate the effect of periodontal disease and smoking on gingival tissues while controlling for between subject differences. Our findings showed that there was a greater number of CD3+, CD20+, CD68+ cells among non-smokers compared with smokers in both healthy and periodontitis sites. However, the ratio of $\mathrm{CD} 45 \mathrm{RO}+$ cell/T cell was greater in smokers. These results were also seen at the sites with periodontitis. $\mathrm{CD} 45 \mathrm{RO}+$ cells are markers of memory mononuclear cells. The increase in the ratio of CD45RO + cells among smokers as compared to nonsmokers may indicate that inflammatory mechanisms due to activity of memory cells might be up-regulated among smokers. It has been reported that cytokines such as IL-1 $\beta$, IL-6 and TNF $\alpha$ are over expressed in gingival tissues of smokers $(15,19,33,34)$. Our group in a previous report, demonstrated that toll like receptors 2 and 4 (TLR2, TLR4) were up-regulated in the gingival tissue of smokers as compared to non-smokers (25). Memory T-cells are one of the subgroups of T cells which are specific for antigen. These cells may persist in 
the site of a previous infection for a long time. Upon repeated exposure to their specific antigen, these cells are capable of rapidly expanding into large number of effects or cells which in turn may give rise to increase in the production of cytokines and other aspects of immune response. It is known that antibody production is impaired among smokers as compared to non-smokers (9). The increase in the proportion of memory T-cells observed in our study, may be explained as an effort of the host system to compensate the impaired mechanisms of antibody production. According to our results, inflammatory mononuclear cells are reduced in the gingival tissue of smokers as compared to non-smokers. This held true for both healthy and periodontitis affected periodontium. Moreover, the proportion of memory T-cells is increased among smoker subjects. Periodontitis sites harbored a greater number of mononuclear cells than healthy sites. One of the limitations of our study was that we did not have a group of periodontally healthy patients. In other words, our healthy sites were from patients who had periodontitis in other areas of their dentition. Perhaps if we had such groups of patients, the differences between healthy and periodontitis sites would have been more pronounced. And finally, further studies using additional markers of host immune response are indicated. Power analysis was performed, and for all markers except CDR45RO, the power was over $90 \%$. The required sample size for CDR45RO marker to achieve acceptable power was 637 cases in each group, which was impossible for us to participate this number of cases in our study.

\section{Conclusions}

Nonsmoker subjects showed significantly greater numbers of CD20+, CD68+, CD3+ cells compared to smoker subjects, both at healthy and periodontitis tissue biopsies. Whereas there was no significant difference in terms of CD45RO. The amount of inflammatory cells including T-cells, macrophages and B-cells in inflamed periodontium was greater than healthy periodontium which proved the role of host defense response to pathogens. Based on our results of this study, the reduction of inflammatory mononuclear cells in both healthy and inflamed periodontium in smokers compared to non-smokers may indicate the immunosuppressive effects of cigarette smoking. This study opens new horizons in the field of immunohistochemistry and its relation to smoking which needs further investigation on different cell types with advanced methods.

\section{Acknowledgments:}

The authors would like to thank the Vice-Chancellor for Research at Mashhad University of Medical Sciences for the financial support of this study (project no. 2258).

\section{Conflict of Interest:}

There is no conflict of interest to be declared.

Authors' contributions:

All authors contributed to this project and article equally. All authors read and approved the final manuscript.

\section{References:}

1) Dahiya, P, Kamal R, Gupta R, Bhardwaj R, Chaudhary $K$, Kaur S. Reactive oxygen species in periodontitis. J Indian Soc Periodontol. 2013; 17(4): 411-6. doi: 10.4103/0972-124x.118306. PMID: 24174716 , PMCID: PMC3800399.

2) Matthews JB, Chen FM, Milward MR, Wright HJ, Carter K, McDonagh A, et al. Effect of nicotine, cotinine and cigarette smoke extract on the neutrophil respiratory burst. J Clin Periodontol. 2011; 38(3): 208-18. doi: 10.1111/j.1600-051X.2010.01676.x. PMID: 21214612.

3) Darveau RP. Periodontitis: a polymicrobial disruption of host homeostasis. Nat Rev Microbiol. 2010; 8(7): 481-90. doi: 10.1038/nrmicro2337. PMID: 20514045.

4) Munz M, Chen H, Jockel-Schneider Y, Adam K, Hoffman P, Berger KA ,et all. A haplotype block downstream of plasminogen is associated with chronic and aggressive periodontitis. J Clin Periodontol. 2017. doi: 10.1111/jcpe.12749. PMID: 28548211.

5) Bascones-Martinez A, Matesanz-Perez P, Escribano-Bermejo M, González-Moles MÁ, Bascones-Ilundain J, Meurman JH. Periodontal disease and diabetes-Review of the literature. Med Oral Patol Oral Cir Bucal. 2011; 16(6): e722-9. doi: 10.4317/medoral.17032. PMID: 21196866.

6) Hernandez M, Dutzan N, Garcia-Sesnich J, Abusleme L, Dezerega A, Silva N, et al. Host-pathogen interactions in progressive chronic periodontitis. J Dent Res. 2011; 90(10): 1164-70. doi: 10.1177/0022034511401405. PMID: 21471325.

7) Katuri KK, Alluri JK, Chintagunta C, Tadiboina N, Borugadda R, Loya M, et all. Assessment of Periodontal Health Status in Smokers and Smokeless Tobacco Users: A Cross-Sectional Study. J Clin 
Diagn Res. 2016; 10(10): ZC143-ZC146. doi: 10.7860/JCDR/2016/22160.8700. PMID: 27891477, PMCID: PMC5121795.

8) Díaz-Faes L, Guerrero A, Magán-Fernández A, Bravo M, Mesa F. Tooth loss and alveolar bone crest loss during supportive periodontal therapy in patients with generalized aggressive periodontitis: retrospective study with follow-up of 8 to 15 years. J Clin Periodontol. 2016; 43(12): 1109-15. doi: 10.1111/jcpe.12596. PMID: 27396322.

9) Yadalam PK, Rajapandian K, Ravishankar PL, Vartharajan K, Subramaniam S, Dinakar M. Evaluation of anticardiolipin antibodies in tobacco users and non-tobacco users with severe chronic periodontal disease. J Int Soc Prev Community Dent. 2016; 6(3): 256-60. doi: 10.4103/2231-0762.183115. PMID: 27382544.

10) Bagaitkar J, Daep CA, Patel CK, Renaud DE, Demuth DR, Scott DA. Tobacco smoke augments Porphyromonas gingivalis-Streptococcus gordonii biofilm formation. PLoS One. 2011; 6(11): e27386. doi: 10.1371/journal.pone.0027386. PMID: 22110637, PMCID: PMC3215692.

11) He CY, Gao XQ, Jiang LP. The impact of smoking on levels of chronic periodontitis-associated biomarkers. Exp Mol Pathol. 2016; 101(1): 110-5. doi: 10.1016/j.yexmp.2016.07.004. PMID: 27450647.

12) Kinane DF, Chestnutt IG. Smoking and periodontal disease. Crit Rev Oral Biol Med. 2000; 11(3): 356-65. doi: 10.1177/10454411000110030501. PMID: 11021635.

13) Moon JH, Lee JH, Lee JY. Subgingival microbiome in smokers and non-smokers in Korean chronic periodontitis patients. Mol Oral Microbiol. 2015; 30(3): 227-41. doi: 10.1111/omi.12086. doi: 10.1111/omi.12086. PMID: 25283067.

14) Takeuchi H, Kubota S, Murakashi E, Zhou Y, Endo K, Ng PS, et al. Nicotine-induced CCN2: from smoking to periodontal fibrosis. J Dent Res. 2010; (89): 34-9. doi: 10.1177/0022034509353403. PMID: 19966042.

15) Carinci F, Palmieri A, Girardi A, Cura F, Scapoli L, Lauritano D. Genetic risk assessment of periodontal disease in healthy patients. Journal of Forensic Research. 2015; 6, no 260. doi: 10.4172/21577145.1000260 .

16) Navarrete M, García J, Dutzan N, Henríquez L, Puente J, Carvajal P, et al. Interferon- $\gamma$, interleukins-6 and 4 , and factor XIII-A as indirect markers of the classical and alternative macrophage activation pathways in chronic periodontitis. J Periodontol. 2014; 85(5): 751-60. doi: 10.1902/jop.2013.130078. PMID: 24070400.

17) Ribeiro FV, Pino DS, Franck FC, Benatti BB, Tenenbaum H, Perio D, et al. Resveratrol Inhibits Periodontitis-Related Bone Loss in Rats Submitted to Cigarette Smoke Inhalation. J Periodontol. 2017: 116. doi: 10.1902/jop.2017.170025. PMID: 28492360.

18) Joshi V, Matthews $C$, Aspiras $M$, de Jager M, Ward M, Kumar P. Smoking decreases structural and functional resilience in the subgingival ecosystem. J Clin Periodontol. 2014; 41(11): 1037-47. doi: 10.1111/jcpe.12300. PMID: 25139209.

19) Toker H, Akpinar A, Aydin H, Poyraz O. Influence of smoking on interleukin-1beta level, oxidant status and antioxidant status in gingival crevicular fluid from chronic periodontitis patients before and after periodontal treatment. J Periodontal Res. 2012; 47(5): 572-7. doi: 10.1111/j.1600-0765.2012.01468.x. PMID: 22364664.

20) Souto GR, Segundo TK, Costa FO, Aguiar MCF, Mesquita RA. Effect of smoking on Langerhans and dendritic cells in patients with chronic gingivitis. J Periodontol. 2011; 82(4): 619-25. doi: 10.1902/jop.2010.100488. PMID: 21054228.

21) Kotsakis GA, Javed F, Hinrichs JE, Karoussis IK, Romanos GE. Impact of cigarette smoking on clinical outcomes of periodontal flap surgical procedures: a systematic review and meta-analysis. Periodontol. 2015; 86(2): 254-63. doi: 10.1902/jop.2014.140452. PMID: 25299388.

22) Angaji M, Gelskey S, Nogueira-Filho G, Brothwell D. A systematic review of clinical efficacy of adjunctive antibiotics in the treatment of smokers with periodontitis. J Periodontol. 2010; 81(11): 1518-28. doi: 10.1902/jop.2010.100192. PMID: 20583918.

23) de Heens GL, Kikkert R, Aarden LA, van der Velden U, Loos BG. Effects of smoking on the ex vivo cytokine production in periodontitis. J Periodontal Res. 2009; 44(1): 28-34. doi: 10.1111/j.16000765.2007.01047.x. PMID: 18973517.

24) Goutoudi P, Diza E, Arvanitidou M. Effect of periodontal therapy on crevicular fluid interleukin-6 and interleukin-8 levels in chronic periodontitis. Int J Dent. 2012; 2012: 362905. doi: 10.1155/2012/362905. PMID: 22114600, PMCID: PMC3205686.

25) Fatemi K, Radvar M, Rezaee A, Rafatpanah H, Azangoo khiavi H, Dadpour Y, et al. Comparison of relative TLR-2 and TLR-4 expression level of disease and healthy gingival tissue of smoking and non- 
smoking patients and periodontally healthy control patients. Aust Dent J. 2013; 58(3): 315-20. doi: 10.1111/adj.12089. PMID: 23981212.

26) Ardais R, Mário Tde G, Boligon J, Kantorski KZ, Moreira CH. The effect of smoking on bleeding on probing after nonsurgical periodontal therapy: a quasi-experimental study. Braz Oral Res. 2014; 28 : 1-7. doi: 10.1590/1807-3107BOR-2014.vol28.0058. PMID: 25337935.

27) Javed F, Al-Kheraif AA, Al Amri MD, Alshehri M, Vohra F, Al-Askar M, et al. Periodontal Status and Whole Salivary Cytokine Profile Among Smokers and Never-Smokers With and Without Prediabetes. J Periodontol. 2015; 86(7): 890-8. doi: 10.1902/jop.2015.140593. PMID: 25672658.

28) Mavropoulos A, Brodin P, Rösing CK, Aass AM, Aars H. Gingival blood flow in periodontitis patients before and after periodontal surgery assessed in smokers and non-smokers. J Periodontol. 2007; 78(9): 1774-82. doi: 10.1902/jop.2007.060472. PMID: 17760548.

29) Bunaes DF, Mustafa M, Mohamed HG, Lie SA, Leknes KN. The effect of smoking on inflammatory and bone remodeling markers in gingival crevicular fluid and subgingival microbiota following periodontal therapy. J Periodontal Res. 2017. doi: 10.1111/jre.12438. PMID: 28306142.

30) Nociti FH Jr, Casati MZ, Duarte PM. Current perspective of the impact of smoking on the progression and treatment of periodontitis. Periodontology 2000. 2015; 67(1): 187-210. doi: 10.1111/prd.12063. PMID: 25494601.

31) Duarte PM, Santos VR, Dos Santos FA, de Lima Pereira SA, Rodrigues DB, Napimoga MH. Role of smoking and type 2 diabetes in the immunobalance of advanced chronic periodontitis. J Periodontol. 2011; 82(3): 429-38. doi: 10.1902/jop.2010.100215. PMID: 20731586.

32) Park KS, Lee Y. Lymphocyte Apoptosis in Smokers and Non-Smokers Following Different Intensity of Exercises and Relation with Lactate. Int J Exerc Sci. 2011; 4(3): 204-16. PMID: 27182363, PMCID: PMC4738908.

33) Haytural O, Yaman D, Ural EC, Kantarci A, Demirel K. Impact of periodontitis on chemokines in smokers. Clin Oral Investig. 2015; 19(5): 979-86. doi: 10.1007/s00784-014-1314-2. PMID: 25193410.

34) Al-Bayaty FH, Baharuddin N, Abdulla MA, Ali HM, Arkilla MB, ALBayaty MF. The influence of cigarette smoking on gingival bleeding and serum concentrations of haptoglobin and alpha 1-antitrypsin. Biomed Res Int. 2013; 2013: 684154. doi: 10.1155/2013/684154. PMID: 24286083, PMCID: PMC3830826. 